\title{
Drug Related Problems in Hospitalized Patients with Kidney Diseases and Clinical Pharmacists' Services- a Prospective Study in China
}

\section{Su Zhang}

Clinical Pharmacy Center, Department of Pharmacy, Zhejiang Provincial People's Hospital, People's Hospital of Hangzhou Medical College

\section{Ping Huang}

Clinical Pharmacy Center, Department of Pharmacy, Zhejiang Provincial People's Hospital, People's Hospital of Hangzhou Medical College

\section{Yan Ren}

Department of Nephrology, Zhejiang Provincial People's Hospital, People's Hospital of Hangzhou Medical College

\section{Bo Lin}

Department of Nephrology, Zhejiang Provincial People's Hospital, People's Hospital of Hangzhou Medical College

\section{Yanfei Shao}

Clinical Pharmacy Center, Department of Pharmacy, Zhejiang Provincial People's Hospital, People's Hospital of Hangzhou Medical College

\section{Xiaolan Ye ( yexl1120@126.com )}

Clinical Pharmacy Center, Department of Pharmacy, Zhejiang Provincial People's Hospital, People's Hospital of Hangzhou Medical College

\section{Research Article}

Keywords: drug related problems, kidney diseases, hospitalized patients, clinical pharmacist

Posted Date: March 1st, 2022

DOI: https://doi.org/10.21203/rs.3.rs-1210943/v1

License: (c) (i) This work is licensed under a Creative Commons Attribution 4.0 International License. Read Full License 


\section{Abstract}

\section{Background}

The patients with kidney diseases are at high risk of Drug related problems (DRPs) because of the multimorbidity associated polypharmacy and pharmacokinetic change. The study aimed to identify DRPs in hospitalized patients with kidney diseases and the effectiveness of clinical pharmacists' service in China.

\section{Methods}

The patients, admitted to the Nephrology department of Zhejiang Provincial People's Hospital between January to December 2020, were enrolled in this prospective study. Clinical pharmacists' service consisted of medication reconciliation, identifying DRPs and providing suggestions. The DRPs were classified using pharmaceutical care net-work Europe (PCNE) DRPs classification system, as well as all data were statistical calculated via SPSS version 26.0.

\section{Results}

From 914 patients with renal disease in the study, $45.95 \%$ of them had at least one DRP. A total of 463 DRPs were identified, and $84.23 \%$ of DRPs were solved with participation of clinical pharmacists. Presence of comorbidities $(A O R=1.187[1.059-1.329])$, polypharmacy $(A O R=1.050[1.031-1.069])$ and hospitalization days $(A O R=1.035[1.001-1.071])$ were predictors of DRPs.

\section{Conclusion}

DRPs were common in the Nephropathy hospitalized patients. Co-morbidities, polypharmacy and extended length of stay could contribute to form DRPs. Clinical pharmacy service is necessary to the optimization of drug therapy in hospitalized patients with kidney diseases.

\section{Background}

The kidney disease, such as chronic kidney disease (CKD) and kidney failure, is becoming increasingly commonplace. Presumably, the global prevalence of all CKD stages was 13.4\% through a 2016 metaanalysis based on 100 studies [1]. According to the China Kidney Disease Network report in 2017, there were almost a half million hemodialysis patients and 132 million patients with renal disease in China [2].

Though drug therapy is essential for the cure and inhibition of the renal function deterioration, it also exposed the patients to drug-related problems (DRPs). According to PCNE, the DRPs, including unnecessary drug therapy, ineffective drug, need additional drug therapy and inappropriate drug dosage or frequency, could certainly or potentially interferes with desired therapeutic outcome [3,4]. DRPs not only affect patients' health seriously, but also bring heavy economic burden to the patients and country. It is estimated that the annual cost of DRPs-related treatment is nearly 177 billion dollars in the United States [5].

Most patients with kidney disease have comorbid conditions (cardiovascular and metabolic disorders, for instance). Complex medication regimens in these patients are very common, that would increase the risk of 
DPRS, including adverse drug reactions (ADRs) and drug interactions [6]. Furthermore, the pharmacokinetic profiles of the renal insufficiency patients are apparently different from normal person. The dose or frequency of drugs which was mainly excreted by kidney, such as levofloxacin, requires adjustment in CKD patients;meanwhile, some drugs, such as NSAIDs, are contraindicated in renal failure patients $[7,8]$. To maintain the effective blood concentration, add an additional medication dose, such as vancomycin, is necessary for hemodialysis patients after dialysis treatment [9]. Thus, the patients with kidney diseases are at high risk of DRPs because of the multi-morbidity associated with polypharmacy and pharmacokinetic change. It has been reported that DRPs prevalence in CKD cases ranging from 12-87\% [10]. So far, no information is available on the incidence and symptom of DRPs in hospitalized patients with kidney diseases in China.

Since the DRPs are substantially prevalent in patients with kidney diseases, discover and correct the DRPs in time are absolutely necessary. Studies in several countries have shown that pharmacist intervention could improve the management of severe DRPs in CKD patients [11, 12]. According to the statistics of Chinese Pharmacists Professional Committee in 2021, with the largest population of kidney patients in the world, only 227 clinical pharmacists of Nephrology there are in China. It is not known whether pharmacists' action on DRPs is affected by the huge population base in nephrology department in China. This study was to observe the systems and the clinical pharmacists' effects of DRPs in hospitalized kidney patients in a large hospital in China.

\section{Methods}

\section{Study design and setting}

The prospective interventional study was conducted from January to December 2020 at Zhejiang Provencal People's Hospital (a 2000-bed comprehensive hospital in China). With the informed consent of patients, the hospitalized kidney sufferers during the study period were included in this study. A professional clinical pharmacists participated in the treatment, thoroughly reviewed the patients' medical records and prescriptions every day, then offered pharmaceutical suggestions.

\section{Data collection and measurement tools}

All the patients' data were collected by clinical pharmacist, including sociodemographic characteristics (age, sex, smoking status, alcohol status), as well as clinical and drug-related information (principal diagnosis, complications, number of drugs prescribed, CKD stage and length of stay).

Identified DRPs were categorized using the Pharmaceutical Care Network Europe (PCNE) v9.00 and all the pharmaceutical recommendations were documented [13]. Based on PCNE v9.00, the intensified DRPS were briefly classified into problem $(P)$, cause $(C)$, intervention( $(I)$, acceptance $(A)$ and Outcome $(0)[13]$.

\section{Statistical analysis}


Descriptive analysis was computed as frequency, mean and standard deviation (SD) for continuous variables and percentage for categorical data. Continuous and categorical variables were analyzed by t test and Chi square test respectively. The determinant of DRPs was detected via logistic regression. SPSS version 26.0 was used for data analysis and a $p$ value $<0.05$ was considered statistically significant.

\section{Results}

\section{Patient characteristics}

A total of 914 patients were included (38.29\% male) during the study. The mean age of the population was $60.23 \pm 17.83$ years. In this study, the proportion of smoker and alcohol user were $19.70 \%$ and $12.14 \%$ respectively. More than half of the patients were diagnosed with stage 5 CKD. On the analysis of comorbid conditions, hypertension (74.84\%) $\square$ diabetes mellitus (34.79\%) पhyperlipemia (31.62\%) and coronary artery disease (13.35\%) were frequently observed,the average of comorbidities was $3.12 \pm 1.31$. The mean mount of medications was $14.74 \pm 8.60$; the average length of stay was $8.76 \pm 4.54$ (Table 1 ). 
Table 1

Demographic and clinical characteristics of the population in the study

\begin{tabular}{|c|c|}
\hline Characteristics & Number(\%) \\
\hline Age, Mean(SD) & $60.23(17.83)$ \\
\hline Male & $350(38.29)$ \\
\hline Smoker & $180(19.70)$ \\
\hline Alcohol user & $111(12.14)$ \\
\hline \multicolumn{2}{|l|}{ Chronic kidney disease stages based on eGFR } \\
\hline CKD $1\left(\mathrm{eGFR} \geq 90 \mathrm{~mL} / \mathrm{min} / 1.73 \mathrm{~m}^{2}\right)$ & $149(16.30)$ \\
\hline CKD 2(eGFR 60-89 mL/min/1.73m²) & $84(9.19)$ \\
\hline CKD 3(eGFR 30-59mL/min/1.73m²) & $56(6.13)$ \\
\hline CKD 4(eGFR 15-29mL/min/1.73m²) & $36(3.94)$ \\
\hline CKD 5(eGFR $\left.₫ 15 \mathrm{~mL} / \mathrm{min} / 1.73 \mathrm{~m}^{2}\right)$ & $589(64.44)$ \\
\hline \multicolumn{2}{|l|}{ comorbidities } \\
\hline Hypertension & $684(74.84)$ \\
\hline Diabetes mellitus & $318(34.79)$ \\
\hline hyperlipemia & $289(31.62)$ \\
\hline Coronary artery disease & $122(13.35)$ \\
\hline Number of comorbid diseases, Mean(SD) & $3.12(1.31)$ \\
\hline Number of prescribed medications, Mean(SD) & $14.74(8.60)$ \\
\hline Number of hospitalization days, Mean(SD) & $8.76(4.54)$ \\
\hline
\end{tabular}

\section{Prevalence And Classification Of Drps Identified Using Pcne V9.00}

During the study involving 914 patients, a total of 463 DRPs were detected with an average of 0.51 DRP per patient. The incidence of DRP detected was 45.95\%. 385 participants(42.12\%)suffered 1 DRP;27 persons (2.95\%) suffered 2 , and 8 patients $(0.88 \%)$ suffered 3 . As shown in Table 2 , the most commonly encountered type of DRP was treat safety related issues (43.84\%) followed by effectiveness (43.20\%). Inapposite drug/dose selection contributed to most of DRPs (89.85\%). The abuse of the antibiotics and cardiovascular agents were the most common causes of the DRPs (32.84\% and 28.66\%) (Fig. 1).Physicians accepted a 
total of $85.53 \%$ pharmaceutical interventions. Finally, $84.23 \%$ of DRPs were solved with participation of clinical pharmacists. 
Table 2

Classification of DRPs identified using PCNE v 9.00

Code Detailed Classification N(\%)

Problems (total

463)

P1 The effectiveness of treatment

200(43.20)

P1.1 No effect of drug treatment

$1(0.5)$

P1.2 Effect of drug treatment not optimal

97(48.5)

P1.3 Untreated symptoms or indication

102(51)

P2

The safety of treatment

203(43.84)

P2.1 Adverse drug event (possibly) occurring

203(100)

P3

Other

60(12.96)

P3.1 Problem with cost-effectiveness of the treatment

20(33.33)

P3.2 Unnecessary drug-treatment

$40(66.66)$

\section{Causes (total}

463)

C1

Drug selection

$279(60.26)$

C1.2 Inappropriate drug

88(31.54)

C1.3 No indication for drug

$37(13.26)$

C1.4 Inappropriate combination of drugs, or drugs and herbal medications, or drugs and dietary supplements

C1.5 Inappropriate duplication of therapeutic group or active ingredient

$9(3.23)$

C1.6 No or incomplete drug treatment in spite of existing indication

$119(42.65)$

C1.7 Too many medicines prescribed for indication

10(3.58)

$\mathrm{C} 2$

Drug form

17(3.67)

C2.1 Inappropriate drug form for this patient

$17(100)$

C3

Dose selection

137(29.59)

C3.1 Drug dose too low

24(17.52)

C3.2 Drug dose too high

83(60.58)

C3.3 Dosage regimen not frequent enough

$6(4.38)$

C3.4 Dosage regimen too frequent

$14(10.22)$

PCNE: Pharmaceutical Care Network Europe; DRP: drug-related problem 
C3.5 Dose timing instructions wrong, unclear or missing

C4

Treatment duration

$5(1.08)$

C4.1 Too short treatment duration

C4.2 Too long treatment duration

C9

Other

C9.1 No or inappropriate monitoring outcome (e.g., TDM)

\section{Intervention}

(total 463)

11

At prescriber level

234(50.54)

I1.3 Intervention proposed to prescriber

48(20.51)

I1.4 Intervention discussed with prescriber

13

At drug level

13.1 Drug changed to

I3.2 Dosage changed to

13.3 Formulation changed to

13.4 Instructions for use changed to

13.5 Drug paused or stopped

13.6 Drug started

\section{Acceptance(total}

463)

A1

Intervention accepted by patient or prescriber

A1.1 Intervention accepted and fully implemented

A1.2 Intervention accepted, implemented partially

A1.3 Intervention accepted but unimplemented

A2

Intervention not accepted

67(14.47)

A2.1 Intervention unaccepted: not feasible

A2.2 Intervention unaccepted: no agreement

A2.4 Intervention unaccepted: unknown reason 


\begin{tabular}{|cclc|}
\hline \multicolumn{2}{|l|}{$\begin{array}{l}\text { Code } \\
\text { Outcome(total } \\
463)\end{array}$} & Detailed Classification & N(\%) \\
\hline 01 & & Solved & $390(84.23)$ \\
\hline & 01.1 & DRP totally solved & $390(100)$ \\
\hline & & Not solved & $73(15.77)$ \\
\hline & 03.1 & DRP not solved, lack of cooperation of patient & $5(6.85)$ \\
\hline & 03.2 & DRP not solved, lack of cooperation of prescriber & $53(72.60)$ \\
\hline PCNE: Pharmaceutical Care Network Europe; DRP: drug-related problem & DRP not solved, intervention not effective & $15(20.55)$ \\
\hline
\end{tabular}

Determinants of DRPs

Comorbid diseases $(A O R=1.187[1.059-1.329])$, polypharmacy $(A O R=1.050[1.031-1.069])$; hospitalization days $(A O R=1.035[1.001-1.071])$ were predictors of DRPs in the multivariate logistics regression model; the $p$ values were $0.003,0.000,0.043$ respectively (Table 3 ). 
Table 3

determinants of DRPs identified using logistic regression.

\begin{tabular}{|c|c|c|c|c|c|c|}
\hline \multirow[t]{2}{*}{ determinates } & \multicolumn{2}{|l|}{ DRP } & \multicolumn{2}{|c|}{$\begin{array}{l}\text { Univariable logistic } \\
\text { regression analysis }\end{array}$} & \multicolumn{2}{|c|}{$\begin{array}{l}\text { Multivariate logistic } \\
\text { regression analysis }\end{array}$} \\
\hline & Yes, N(\%) & No, N(\%) & $\operatorname{COR}(95 \% \mathrm{Cl})$ & $\begin{array}{l}P \\
\text { value }\end{array}$ & AOR(95\%Cl) & $\begin{array}{l}P \\
\text { value }\end{array}$ \\
\hline Age, Mean(SD) & $\begin{array}{l}62.40 \pm \\
17.37\end{array}$ & $\begin{array}{l}58.36 \pm \\
18.02\end{array}$ & $\begin{array}{l}1.013 \\
(1.006- \\
1.021)\end{array}$ & 0.001 & $\begin{array}{l}1.001(0.993- \\
1.010)\end{array}$ & 0.771 \\
\hline \multicolumn{7}{|l|}{ Gender } \\
\hline Female & 265(63.10) & 299(60.52) & Reference & & & \\
\hline Male & 155(36.90) & 195(39.47) & $\begin{array}{l}0.897 \\
(0.686- \\
1.173)\end{array}$ & 0.426 & & \\
\hline \multicolumn{7}{|l|}{$\begin{array}{l}\text { Smoking } \\
\text { status }\end{array}$} \\
\hline No & 331(78.81) & $403(81.58)$ & Reference & & & \\
\hline Yes & $89(21.19)$ & $91(18.42)$ & $\begin{array}{l}1.191(0.859- \\
1.650)\end{array}$ & 0.294 & & \\
\hline \multicolumn{7}{|l|}{ Alcohol user } \\
\hline No & 365(86.90) & 438(88.66) & Reference & & & \\
\hline Yes & $55(13.10)$ & $56(11.34)$ & $\begin{array}{l}1.179(0.792- \\
1.753)\end{array}$ & 0.417 & & \\
\hline \multicolumn{7}{|l|}{$\begin{array}{l}\text { Renal function } \\
\text { based on eGFR }\end{array}$} \\
\hline CKD1 & $48(11.43)$ & 101(20.45) & Reference & & Reference & \\
\hline CKD2 & $32(7.62)$ & $52(10.53)$ & $\begin{array}{l}1.295(0.741- \\
2.264)\end{array}$ & 0.365 & $\begin{array}{l}0.977(0.542- \\
1.761)\end{array}$ & 0.939 \\
\hline CKD3 & $23(5.48)$ & $33(6.68)$ & $\begin{array}{l}1.467(0.778- \\
2.764)\end{array}$ & 0.236 & $\begin{array}{l}1.132(0.583- \\
2.198)\end{array}$ & 0.714 \\
\hline CKD4 & $23(5.48)$ & $13(2.63)$ & $\begin{array}{l}3.723(1.738- \\
7.976)\end{array}$ & 0.001 & $\begin{array}{l}2.342(1.045- \\
5.253)\end{array}$ & 0.039 \\
\hline CKD5 & $294(70)$ & 295(59.72) & $\begin{array}{l}2.097(1.435- \\
3.065)\end{array}$ & 0.000 & $\begin{array}{l}1.249(0.809- \\
1.927)\end{array}$ & 0.315 \\
\hline $\begin{array}{l}\text { Comorbid } \\
\text { diseases, } \\
\text { Mean(SD) }\end{array}$ & $3.34 \pm 1.45$ & $2.93 \pm 1.15$ & $\begin{array}{l}1.272(1.148- \\
1.410)\end{array}$ & 0.000 & $\begin{array}{l}1.187(1.059- \\
1.329)\end{array}$ & 0.003 \\
\hline
\end{tabular}

COR: crude odds ratio; AOR: adjusted odds ratio; Cl: confidence interval 


\begin{tabular}{|c|c|c|c|c|c|c|}
\hline \multirow[t]{2}{*}{ determinates } & \multicolumn{2}{|l|}{ DRP } & \multicolumn{2}{|c|}{$\begin{array}{l}\text { Univariable logistic } \\
\text { regression analysis }\end{array}$} & \multicolumn{2}{|c|}{$\begin{array}{l}\text { Multivariate logistic } \\
\text { regression analysis }\end{array}$} \\
\hline & Yes, N(\%) & No, N(\%) & $\operatorname{COR}(95 \% \mathrm{Cl})$ & $\begin{array}{l}P \\
\text { value }\end{array}$ & AOR(95\%Cl) & $\begin{array}{l}P \\
\text { value }\end{array}$ \\
\hline $\begin{array}{l}\text { Prescribed } \\
\text { medications, } \\
\text { Mean(SD) }\end{array}$ & $\begin{array}{l}17.00 \pm \\
9.20\end{array}$ & $\begin{array}{l}12.86 \pm \\
7.58\end{array}$ & $\begin{array}{l}1.062(1.044- \\
1.080)\end{array}$ & 0.000 & $\begin{array}{l}1.050(1.031- \\
1.069)\end{array}$ & 0.000 \\
\hline $\begin{array}{l}\text { Hospitalization } \\
\text { days, } \\
\text { Mean(SD) }\end{array}$ & $9.56 \pm 4.46$ & $8.08 \pm 4.51$ & $\begin{array}{l}1.076 \\
(1.044- \\
1.108)\end{array}$ & 0.000 & $\begin{array}{l}1.035(1.001- \\
1.071)\end{array}$ & 0.043 \\
\hline
\end{tabular}

\section{Discussion}

DRPs is common during the treatment of CKD patients due to multi-morbidity associated polypharmacy and pharmacokinetic change. By far, this is the first study to observe the incidence and symptoms of DRPs in inpatients with renal disease in a Chinese large-scale hospital.

The frequency of DRPs (45.95\%)in 914 nephropathic patients with an average of 0.51 DRP per patient, within the scope reviewed by the interval documented (12-87\%)[10]. A total of 463 DRPs were detected. These data suggest that similar to the other countries, the DRPs is also familiar in patients with kidney disease in China.

The major reasons of DRPs were drug/dose selection (89.85\%) using PCNE v9.00, a general DRP analysis method [13]. In terms of drug selection, the irrational use of antibiotics (32.84\%) and cardiovascular agents (28.66\%) were the main reason, which is similar to other studies [14-16]. We found that the most common comorbidities of CKD patients were hypertension (74.84\%) and diabetes mellitus (34.79\%), that might explain why the abuse of cardiovascular agents were universal. The DRPs related cardiovascular agents were largely due to the unreasonable drug combination and inappropriate drug selection in this study. For instance, it has been observed that losartan potassium hydrochlorothiazide tablet combined with irbesartan tablet. This is a typical irrational drug combination on account of the both drugs containing the same mechanism composition (losartan, irbesartan). Long-term use of Clonidine was inappropriate for CKD patients because of central nervous system suppression function. Whereas, the wrong dosage and treatment course contributed the majority of DRPs involved anti-microbials. Most antibacterial drugs, including levofloxacin, vancomycin and part of $\beta$-lactams, need dose adjustment accompanied by deterioration of renal function. However, we found that the dosage of the antibacterial in the prescription of CKD patients were usually higher than that allowed by instructions. In addition, some antibacterial agents, such as metronidazole, needed no dosage adjustment in CKD patients. Hence, incorrect antibacterial drug dosage was a common problem, which could lead to poor anti-infective treatment effect or aggravate kidney dysfunction. 
The valuable contribution of pharmacists to drug therapy in CKD patients, including drug dosage adjustment, adverse reaction detection, blood concentration monitoring and medical education, has been documented in 2 systematic reviews $[17,18]$. 85.53\% of pharmacist's suggestions on medicines were accepted by clinician, and $84.23 \%$ of DRPs were solved. The advice on medicine dosage adjustment was easy to accept. By contrast, pharmacist would face more difficulties when recommending doctors to replace the drug regimen in our observation. Compared to perindopril, fosinophil is more difficult to remove by dialysis due to the high plasma protein binding rate. In a hemodialysis patient with hypertension, clinical pharmacist's suggestion concerning replacing perindopril with fosinophil was not adopted in this study. Some suggestions were rejected by patients for cost. Blood concentration monitoring of immunosuppressant, such as cyclosporin A and tacrolimus, was often remarkably difficult to implement by reason of the high price and long waiting time. Physician and patients, in general, accepted the vast majority of recommendations of pharmacist.

Comorbidity and polypharmacy are the factors in the occurrence of DRPs, which had been proved in several studies $[4,16,19]$. Length of hospitalization longer than 5 days would increase the possibility of DRPs in 2 research results $[19,20]$. We got the similar conclusions in this study, comorbid diseases, polypharmacy and hospitalization days were predictors of DRPs whether in univariable or multivariate logistics regression model.

Some studies results support that stage of CKD was the independent risk factors for DRPs [4, 19-21]. We found that only renal insufficiency on stage 4 was remarkably correlated with DRPs via multivariate logistic regression analysis. The possible reasons are as follows: patients with the final stage of the renal insufficiency (CKD5) were receiving regular dialysis usually, who will easily get more attention from clinician. Besides, the nephrologists clearly know whether the medicine is appropriate and how to adjust the dose in dialysis patients. We observed that tailored approach for CKD patients at stage 4 might be more complicated and difficult for doctors. Dapagliflozin, for instance, is forbidden in dialysis patients; whereas, many clinicians ignore that it is also contraindicated when eGFR is under $30 \mathrm{ml} / \mathrm{min} / 1.73 \mathrm{~m}^{2}$. These data might remind us the sever renal insufficiency patients with or without undergoing dialysis, long for more care from both clinicians and pharmacists.

\section{Limitations}

To our knowledge, this is the first study to evaluate the prevalence of DRPs and clinical pharmacist's effects in the hospitalized patients with renal insufficiency in a large Chinese hospital. However, there are also some limitations. Firstly, there is a lack of comparative data on pharmacist's intervention with DRPs. Further randomized controlled studies are needed for more accurate conclusions. Secondly, there are far too few pharmacist-only 227 clinical pharmacists specializing in nephrology in China, extremely low by world standards. Thus, only one clinical pharmacist there was in department of nephrology. The incidence of DRPs in this study might be underestimated.

\section{Conclusion}


This study confirms that the prevalence of DRPs is high among CKD hospitalized patients in China. Comorbidities, polypharmacy and extended length of stay are the risk factors of DRPs. Clinical pharmacy service in the care of CKD patients is of great value.

\section{Abbreviations}

DRP

Drug related problems

CKD

chronic kidney disease

PCNE

pharmaceutical care network of Europe

ADR

adverse drug reactions

\section{Declarations}

\section{Acknowledgements}

Not applicable.

\section{Author's contributions}

SZ designed and performed the research, wrote the manuscript. PH, YR, BL, YFS and XLY contributed to the presentation of the data and corrected the manuscript. All the authors have read and approved the manuscript.

\section{Funding}

The study was funded by the Public welfare Program of the Science and Technology Department of Zhejiang Province(LGF20H310005); Zhejiang Provincial Project for Medical and Health Science and Technology(2022KY063,2020KY051); and Special scientific research fund project of Hospital Pharmacy of

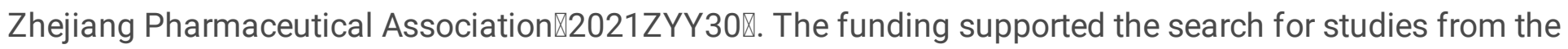
databases and writing the manuscript.

\section{Availability of data and materials}

All data generated during this study are included in this published article. The dataset analyzed during the study is available from the corresponding author upon reasonable request.

\section{Ethics approval and consent to participate}

All intervention process in this study were approved by Ethics Committee of Zhejiang Provincial People's Hospital. Participation of patients was entirely voluntary. Each participant or its legal guardian was asked to sign a written informed consent before data collection and pharmacist's intervention. All methods were 
carried out in accordance with relevant guidelines and regulations. The right of participants not to participate was respected. The patient confidentiality and data information are strictly protected.

\section{Consent of publication}

Not applicable.

\section{Conflicts of Interest}

Not applicable.

\section{Competing interests}

All authors declare no competing interests in this study.

\section{References}

1. Hill NR, Fatoba ST, Oke JL, Hirst JA, O'Callaghan CA, Lasserson DS, Hobbs FD. Global Prevalence of Chronic Kidney Disease - A Systematic Review and Meta-Analysis. PLoS One. 2016; 11(7): e0158765.

2. GBD Chronic Kidney Disease Collaboration. Global,regional,and national burden of chronic kidney disease,1990-2017: a systematic analysis for the Global Burden of Disease Study 2017.Lancet. 2020; 395(10225):709-733.

3. Subeesh VK, Abraham R, Satya Sai MV, Koonisetty KS. Evaluation of prescribing practices and drugrelated problems in chronic kidney disease patients: A cross-sectional study. Perspect Clin Res. 2020;11(2):70-74.

4. Garedow AW, Mulisa Bobasa E, Desalegn Wolide A, Kerga Dibaba F, Gashe Fufa F, Idilu Tufa B, Debalke S, Kumela Goro K. Drug-Related Problems and Associated Factors among Patients Admitted with Chronic Kidney Disease at Jimma University Medical Center, Jimma Zone, Jimma, Southwest Ethiopia: A Hospital-Based Prospective Observational Study. Int J Nephrol. 2019; 2019:1504371.

5. Ayalew MB, Megersa TN, Mengistu YT. Drug-related problems in medical wards of Tikur Anbessa specialized hospital, Ethiopia. J Res Pharm Pract. 2015;4(4):216-221.

6. Tonelli M, Wiebe N, Guthrie B, James MT, Quan H, Fortin M, Klarenbach SW, Sargious P, Straus S, Lewanczuk R, Ronksley PE, Manns BJ, Hemmelgarn BR. Comorbidity as a driver of adverse outcomes in people with chronic kidney disease. Kidney Int. 2015;88(4):859-866.

7. Montero Muñoz J, Solla Suárez PE, Gutiérrez Rodríguez J. Estimación del filtrado glomerular en el paciente anciano. Implicaciones clínicas en el uso de antibióticos [Estimation of glomerular filtration rate in the elderly patient: Clinical implications in the use of antibiotics]. Rev Esp Geriatr Gerontol. 2021; 56(5): 268-271.

8. Hoff BM, Maker JH, Dager WE, Heintz BH. Antibiotic Dosing for Critically III Adult Patients Receiving Intermittent Hemodialysis, Prolonged Intermittent Renal Replacement Therapy, and Continuous Renal Replacement Therapy: An Update. Ann Pharmacother. 2020;54(1):43-55. 
9. Crew P, Heintz SJ, Heintz BH. Vancomycin dosing and monitoring for patients with end-stage renal disease receiving intermittent hemodialysis. Am J Health Syst Pharm. 2015;72(21):1856-1864.

10. Alruqayb WS, Price MJ, Paudyal V, Cox AR. Drug-Related Problems in Hospitalised Patients with Chronic Kidney Disease: A Systematic Review. Drug Saf. 2021;44(10):1041-1058.

11. Khokhar A, Khan YH, Mallhi TH, Khan HM, Alotaibi NH, Alzarea Al, Bokharee N. Effectiveness of pharmacist intervention model for chronic kidney disease patients; a prospective comparative study. Int J Clin Pharm. 2020;42(2):625-634.

12. Quintana-Bárcena P, Lord A, Lizotte A, Berbiche D, Lalonde L. Prevalence and Management of DrugRelated Problems in Chronic Kidney Disease Patients by Severity Level: A Subanalysis of a Cluster Randomized Controlled Trial in Community Pharmacies. J Manag Care Spec Pharm. 2018;24(2):173181.

13. Pharmaceutical Care Network Europe (PCNE) DRP Classification V9.00. Available online: https://www.pcne.org/upload/files/410_PCNE_classification_V9-0m.pdf

14. Yang P, Chen N, Wang RR, Li L, Jiang SP. Inappropriateness of medication prescriptions about chronic kidney disease patients without dialysis therapy in a Chinese tertiary teaching hospital. Ther Clin Risk Manag. 2016; 12:1517-1524.

15. Prajapati A, Ganguly B. Appropriateness of drug dose and frequency in patients with renal dysfunction in a tertiary care hospital: A cross-sectional study. J Pharm Bioallied Sci. 2013; 5(2):136-140.

16. Saleem A, Masood I. Pattern and Predictors of Medication Dosing Errors in Chronic Kidney Disease Patients in Pakistan: A Single Center Retrospective Analysis. PLoS One. 2016;11(7): e0158677.

17. Salgado TM, Moles R, Benrimoj SI, Fernandez-Llimos F. Pharmacists' interventions in the management of patients with chronic kidney disease: a systematic review. Nephrol Dial Transplant. 2012;27(1):276292.

18. Stemer G, Lemmens-Gruber R. Clinical pharmacy activities in chronic kidney disease and end-stage renal disease patients: a systematic literature review. BMC Nephrol. 2011; 12: 35.

19. Saleem A, Masood I, Khan TM. Clinical relevancy and determinants of potential drug-drug interactions in chronic kidney disease patients: results from a retrospective analysis. Integr Pharm Res Pract. 2017; 6: 71-77.

20. Prajapati A, Ganguly B. Appropriateness of drug dose and frequency in patients with renal dysfunction in a tertiary care hospital: A cross-sectional study. J Pharm Bioallied Sci. 2013;5(2):136-140.

21. Sheen SS, Choi JE, Park RW, Kim EY, Lee YH, Kang UG. Overdose rate of drugs requiring renal dose adjustment: data analysis of 4 years prescriptions at a tertiary teaching hospital. J Gen Intern Med. 2008;23(4):423-428.

\section{Figures}




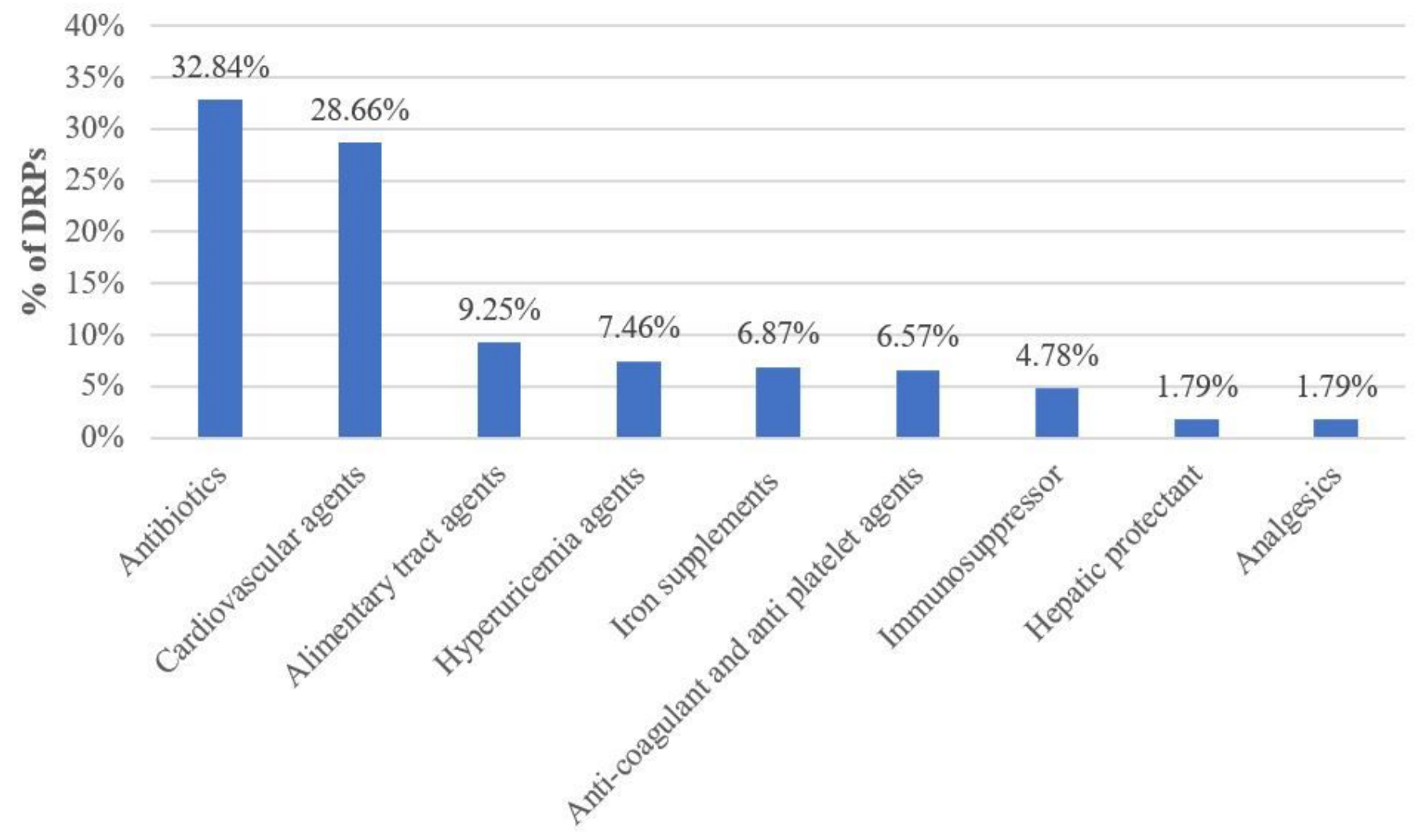

Figure 1

Classification of the drugs related to DRPs 